\title{
Patterns of Clinical Care Subsequent to Nonindicated Vitamin D Testing in Primary Care
}

\author{
Michelle S. Rockwell, PhD, RD, YingXing Wu, MD, MS, Mariana Salamoun, MA, \\ Matthew W. Hulver, PhD, and John W. Epling, MD, MSEd
}

Background: Exponential increases in nonindicated, low-value vitamin D testing have been reported over the past 15 years. Downstream effects of such testing have not been well quantified.

Methods: The purpose of this study was to describe patterns of vitamin D testing within primary care of a large regional health system and to explore downstream health service utilization subsequent to nonindicated testing. Instances of vitamin D testing in 2015 were obtained by an electronic health record-automated search. A subset of patients for whom vitamin D testing was classified as nonindicated was identified, and vitamin D-related service utilization was tracked for 24 months.

Results: Of the 77,836 adult primary care patient records identified in 2015 , vitamin $D$ tests were conducted on $8,042(10.3 \%)$, with $24.3 \%$ of tests yielding abnormal results. In the nonindicated test subset $(n=574)$, substantial clinical variability was illustrated by 85 care pathways and 26 vitamin $D$ prescriptions. Forty-five percent of abnormal vitamin D lab tests were not followed up with repeat vitamin D tests. Vitamin D-related services (laboratory tests, imaging, and prescriptions) occurred at an average rate of 1.6 services per patient during the 24 months following nonindicated vitamin $D$ testing. Some of these services were also classified as nonindicated.

Conclusions: Evidence of a health service cascade following nonindicated vitamin D testing exists. opportunities for improved consistency and quality of care related to vitamin $\mathrm{D}$ were observed in our health system. These results may inform clinical pathways related the prevention, evaluation, and treatment of low vitamin D. (J Am Board Fam Med 2020;33:569-579.)

Keywords: Electronic Health Record, Low Value Care, Overuse, Primary Health Care, Quality Improvement, Uncertainty, 25-hydroxyvitamin D

\section{Introduction}

Over 25\% (\$760 to $\$ 932$ billion annually) of US health care spending is considered unnecessary and wasteful. ${ }^{1}$ Low value care, which is defined as clinical services that confer minimal or no benefit or may cause harm, is a substantial component of unnecessary health care expenditures. ${ }^{2,3}$ The Choosing

This article was externally peer reviewed.

Submitted 6 January 2020; revised 3 April 2020; accepted 8 April 2020.

From Department of Human Nutrition, Foods, and Exercise, Virginia Tech, Blacksburg (MSR, MWH); Center for Transformative Research on Health Behaviors, Fralin Biomedical Research Institute at Virginia Tech Carilion, Roanoke (MSR, MWH, JWE); Health Analytics Research Team, Carilion Clinic, Roanoke, VA (YW, MS); Department of Family and Community Medicine, Carilion Clinic, Roanoke, VA (JWE); Virginia Tech Carilion School of Medicine, Roanoke (JWE).

Funding: The project was supported by the Center for Transformative Research on Health Behaviors, Fralin Biomedical Research Institute at Virginia Tech Carilion, Roanoke, VA.
Wisely Campaign is an initiative aimed at reducing low value care and highlighting clinical practices inconsistent with the evidence. ${ }^{4,5}$ Initially founded in 2012 by the American Board of Internal Medicine Foundation, Choosing Wisely includes recommendations from over 80 professional medical societies. ${ }^{4}$

Three medical societies have identified a Choosing Wisely recommendation of Do not order population-based screening for vitamin $D .^{6}$ This recommendation aligns with a 2014 US Preventive Services Task Force recommendation statement that advises against vitamin $\mathrm{D}$ screening in asymptomatic community-dwelling adults due to

Conflicts of interest: The authors have no conflicting or competing interests to disclose.

Corresponding author: Michelle Rockwell $\mathrm{PhD}, \mathrm{RD}$, Department of Human Nutrition, Foods, and Exercise, Virginia Tech, 258 Wallace Hall, Blacksburg, VA 24061 (Email: msrock@vt.edu). 
Table 1. Indicators for Vitamin D Testing

\begin{tabular}{|c|c|c|}
\hline Category of Indication* & ICD-10 Text Diagnosis & ICD-10 Code $(\mathrm{s})^{\dagger}$ \\
\hline \multirow{7}{*}{$\begin{array}{l}\text { Vitamin D deficiency or } \\
\text { insufficiency, osteomalacia, } \\
\text { rickets }\end{array}$} & Rickets, active & E55.0 \\
\hline & Vitamin D deficiency, unspecified & E55.9 \\
\hline & Sequelae of rickets & E64.3 \\
\hline & Adult osteomalacia & M83 \\
\hline & Adult osteomalacia due to malnutrition & M83.3 \\
\hline & Disorder of bone density and structure, unspecified & M85.9 \\
\hline & Disorder of bone, unspecified & M89.9 \\
\hline \multirow[t]{2}{*}{ Osteoporosis, osteopenia } & Osteoporosis with current pathological fracture & M80 \\
\hline & Osteoporosis without current pathological fracture & M81 \\
\hline \multirow{2}{*}{$\begin{array}{l}\text { Pathological fracture or } \\
\text { stress fracture }\end{array}$} & Stress fracture & M84.3 \\
\hline & Pathological fracture & M84.4 \\
\hline \multirow{6}{*}{$\begin{array}{l}\text { Malabsorption or } \\
\text { inflammatory bowel } \\
\text { disease }\end{array}$} & Crohn's disease [regional enteritis] & $\mathrm{K} 50$ \\
\hline & Ulcerative colitis & K51 \\
\hline & $\begin{array}{l}\text { Celiac disease, tropical sprue, blind loop syndrome, pancreatic steatorrhea, } \\
\text { other malabsorption due to intolerance }\end{array}$ & K90.0-K90.4 \\
\hline & Other intestinal malabsorption & K90.89 \\
\hline & Intestinal malabsorption, unspecified & K90.9 \\
\hline & Postsurgical malabsorption, not elsewhere classified & K91.2 \\
\hline \multirow{5}{*}{$\begin{array}{l}\text { Parathyroid, calcium, or } \\
\text { phosphate disorder }\end{array}$} & Idiopathic hypoparathyroidism & E20.0 \\
\hline & Hypoparathyroidism, unspecified & E20.9 \\
\hline & Secondary hyperparathyroidism & E21.0-E21.5 \\
\hline & Hypocalcemia & E83.51 \\
\hline & Hypercalcemia & E83.52 \\
\hline Chronic kidney disease & Chronic kidney disease, stages 3-5; end-stage renal disease & N18.3-18.5; N18.6 \\
\hline
\end{tabular}

*Indicators for vitamin D testing based on Choosing Wisely criteria. ${ }^{1}$

${ }^{\dagger}$ Patients with a diagnosis of any of these ICD-10 codes were excluded from the subset of patients identified as having nonindicated vitamin D testing in 2015.

ICD-10, International classification of diseases, tenth revision.

insufficient evidence of benefits and harms. ${ }^{7}$ The US Endocrine Society and the National Academy of Medicine (formerly known as the Institute of Medicine) also recommend against vitamin D testing in low-risk populations. ${ }^{8,9}$ Choosing Wisely and others do recognize, however, that vitamin D testing is indicated in patients at high risk for abnormal vitamin D or related complications (ie, osteoporosis or osteopenia, parathyroid or calciumrelated disorder, or chronic kidney disease of $\geq$ stage 3) (Table 1). ${ }^{6,10}$

At $\$ 100$ to $\$ 300$ per test, vitamin D testing is itself a low to moderately priced laboratory test. ${ }^{11}$ However, the large volume of tests regularly conducted makes vitamin D testing a significant economic investment. ${ }^{10,12}$ It has been estimated that over 1 billion vitamin $\mathrm{D}$ tests are ordered annually worldwide ${ }^{13}$ and that test ordering has increased substantially over the past 15 years. ${ }^{14-18}$ Between 25\% and $77 \%$ of these tests follow a pattern of nonindicated screening rather than targeted testing of high-risk patients. ${ }^{11,19-22}$ Six million vitamin D tests labeled as "low value" were conducted in commercial and Medicare-insured Americans in 2014, tallying over $\$ 800$ million. In addition, \$24 million was spent on vitamin D testing considered nonindicated just in the state of Virginia in $2016 .^{23}$ Recently, insurance providers have implemented stricter guidelines on vitamin D test reimbursement. ${ }^{24}$

Along with financial burden, overuse of screening and diagnostic tests has been associated with increased risk of patient harm. ${ }^{25-28}$ Further research is needed to examine downstream effects and consequences of nonindicated vitamin D testing. The purpose of this study was to describe vitamin $\mathrm{D}$ test ordering patterns and explore downstream consequences of nonindicated vitamin D test ordering within primary care of a regional health system. 


\section{Methods}

\section{Study Design}

An automated search of the electronic health record (EHR) database for a regional health system was performed to identify instances of vitamin D testing in adult, continuous care patients in 2015. Vitamin D testing was defined as a single 25-hydroxyvitamin D $[25(\mathrm{OH}) \mathrm{D}]$ test. We also identified a subset of vitamin D tests that were ordered without clinical indication and tracked vitamin D-related laboratory testing, imaging services, and prescriptions incurred during the 24 months following the index vitamin D test. For the purpose of this study, nonindicated vitamin D testing was defined as vitamin $\mathrm{D}$ tests that do not meet Choosing Wisely criteria for indicated services (Table 1). ${ }^{6}$ This study was approved by the institutional review board of Carilion Clinic (IRB-18274). The Strengthening the Reporting of Observational Studies in Epidemiology (STROBE) Statement checklist for observational studies was used in the preparation of this manuscript. ${ }^{29}$

\section{Setting}

Carilion Clinic is a nonprofit comprehensive health care system that serves over 1 million patients in Southwest Virginia. Adult primary care services at Carilion Clinic are delivered by 226 family medicine clinicians and 22 internal medicine clinicians (physicians, physicians assistants, and nurse practitioners) in 54 different facilities. Epic (Epic Systems, Wisconsin, US) has served as the EHR platform for Carilion Clinic since 2008, and Quest Diagnostics (New Jersey, US) has served as the laboratory services provider for Carilion Clinic since 2014. Vitamin D test analyses are conducted using an immunoassay methodology certified by the Centers for Disease Control and Prevention Vitamin D Standardization Certification Program. Carilion Clinic assigns 30 to $100 \mathrm{ng} / \mathrm{mL}$ as the normal

Table 2. Vitamin D Test Result Reference Range

\begin{tabular}{lc}
\hline Category & 25(OH)D $(\mathrm{ng} / \mathrm{mL})^{*}$ \\
\hline Low & 0 to 29.9 \\
Vitamin D deficient & 0 to 19.9 \\
Vitamin D insufficient & 20 to 29.9 \\
Normal & 30 to 99.9 \\
High & $>100$ \\
\hline
\end{tabular}

*Vitamin D test result reference range based on the reference range established by Carilion Clinic and Quest Diagnostics². reference range for $25(\mathrm{OH}) \mathrm{D}$ (Table 2$)$. Within our health system, ICD-10 codes are assigned at the time that laboratory tests are ordered.

\section{Data Extraction}

From Carilion Clinic's EHR, we identified adult patients ( $\geq 18$ years of age) who received ongoing care ( $\geq 1$ visit annually) from 1 or more primary care clinicians between January 1, 2013 and December 31, 2017. Data were extracted for any of these continuous primary care patients for whom an outpatient initial vitamin $\mathrm{D}$ test (ie, first test within 12 months) was conducted between January 1, 2015 and December 31, 2015. In addition to vitamin D test date and test results, we also extracted the following data: age, gender, race/ethnicity, body mass index (BMI), insurer, and diagnoses code(s) associated with the vitamin D test.

A subset of patients for whom the initial vitamin $\mathrm{D}$ test was considered nonindicated was established through the identification of patients who did not have diagnoses shown in Table 1 , had no previous vitamin $\mathrm{D}$ test(s) documented anywhere in their history, and had not received a vitamin $\mathrm{D}$ prescription in the 12 months before their index vitamin $\mathrm{D}$ test. The following additional vitamin D-related service data documented in the 24 months subsequent to the nonindicated vitamin $\mathrm{D}$ test were extracted for this subset: laboratory tests $[25(\mathrm{OH}) \mathrm{D}, 1,25(\mathrm{OH}) 2 \mathrm{D}$, calcium, phosphorus, alkaline phosphatase, and parathyroid hormone $(\mathrm{PTH})]$, prescriptions (vitamin D preparations $>400 \mathrm{IU}$, osteoporosis medications, and calcimimetic medications), imaging services (bone mineral density), and diagnoses.

\section{Data Analysis}

Data were analyzed using IBM Statistical Package for the Social Sciences (SPSS) version 26.0 (Chicago, IL). Descriptive statistics (means, standard deviation, and frequencies) were calculated on all data. Differences between means were evaluated using the unpaired $t$ test or one-way analysis of variance with Tukey's multiple comparisons test. For categorical data, $\chi^{2}$ and Fisher's exact tests were used. Multivariate linear regression analysis was used to evaluate the contribution of patient factors to vitamin $\mathrm{D}$ test results. Poisson regression analysis was used to evaluate the contribution of patient factors to number of services incurred. 
Statistical significance was set at an $\alpha$ level of 0.05. Plotly R Package version 4 (Quebec, Canada) was used to create an alluvial diagram.

\section{Results}

We identified 77,836 continuously enrolled adult primary care patient records for 2015. Vitamin D tests were conducted on 8042 of these patients (10.3\%). The nonindicated vitamin D test subset included 574 patients. Patients in the nonindicated vitamin $\mathrm{D}$ test subset were younger, more likely to be male, more likely to be commercially insured or self-pay, and less likely to be insured by Medicare compared with all patients who had vitamin D testing (Table 3).

\section{Vitamin D Test Results}

Vitamin D test results were similar among the nonindicated and indicated vitamin D test groups (Table 4), but the nonindicated vitamin $\mathrm{D}$ test subset included a greater proportion of abnormal test results $(39.5 \%)$ than those who had indicated tests $(24.3 \%)(P<.001)$ (Table 4). Vitamin D test results did not differ by patient age. White patients had 18\% higher vitamin $\mathrm{D}$ test results than black or African American, Asian, and Hispanic patients $(P<.001)$. Patients with underweight $\left(<18.5 \mathrm{~kg} / \mathrm{m}^{2}\right)$ or normal BMI (18.5 to $25 \mathrm{~kg}$ / $\mathrm{m}^{2}$ ) had higher (17\% and $15 \%$, respectively) vitamin D test results than patients with a BMI of $>25 \mathrm{~kg} / \mathrm{m}^{2}$ $(P<.001)$ as did those with commercial insurance or self-pay status compared with other insurers (Medicare, Medicaid, and other) $(P<.001)$.

\section{Downstream Services following Nonindicated Vitamin D Testing}

A total of 4437 vitamin D-relevant laboratory, prescription, and imaging services were ordered for patients who had nonindicated vitamin $\mathrm{D}$ testing over the 24-month observation period. Because the volume of calcium $(\mathrm{n}=2184)$ and alkaline phosphatase $(n=1412)$ tests ordered was disproportionate to other laboratory tests and because they are part of common test panels (basic metabolic panel and comprehensive metabolic panel, respectively), they were omitted from primary analyses. Thus, we observed a total of 841 vitamin D-relevant laboratory $(n=466)$, prescription $(\mathrm{n}=344)$, and imaging $(\mathrm{n}=31)$ services during the 24 months following a nonindicated vitamin D test. The provision of these services followed 85 different clinical pathways (ie, steps and timing of vitamin D-related care; data not shown).
Based on Poisson analysis, gender, race, age, insurer, month of test, and index vitamin $\mathrm{D}$ test result category (deficient, insufficient, normal, and high) did not predict the number of services incurred. Figure 1 shows the flow of vitamin Drelevant services observed in the nonindicated vitamin $\mathrm{D}$ test subset based on results of the index vitamin D test.

\section{Laboratory Testing Subsequent to Nonindicated Vitamin D Testing}

Follow-up vitamin D testing was conducted in 200 patients $(34.8 \%)$ in the nonindicated vitamin $\mathrm{D}$ test subset. The time lapse between initial and followup test(s) varied broadly (2 to 718 days), but 19 (5.9\%) follow-up vitamin D tests took place sooner than 8 weeks after the nonindicated test. The number of follow-up tests conducted over 24 months was 1 (129 patients), 2 (37 patients), 3 (23 patients), 4 (9 patients), 5 (1 patient), or 7 (1 patient). No follow-up vitamin D testing was conducted in $61.7 \%$ of patients with abnormal vitamin $\mathrm{D}$ test results. Of the 320 total follow-up vitamin D tests conducted, 194 (60.6\%) occurred in patients with normal vitamin $\mathrm{D}$ test results in their most recent vitamin D test. Patients with insufficient initial vitamin $\mathrm{D}$ test results had a 2-fold greater likelihood of follow-up vitamin $\mathrm{D}$ tests than patients with deficient test results and a 5 -fold greater likelihood than those with normal test results $(P=.022)$.

Other vitamin D-relevant laboratory tests included PTH ( $\mathrm{n}=281)$, phosphorus ( $\mathrm{n}=123)$, and $1,25(\mathrm{OH}) 2 \mathrm{D}(\mathrm{n}=62)$. Abnormal test results were observed with 33.3\% (PTH), 23.6\% (phosphorus), and $20.0 \%[1,25(\mathrm{OH}) 2 \mathrm{D}]$ of these tests. There was no relationship between initial vitamin $\mathrm{D}$ test result and likelihood of having a $1,25(\mathrm{OH}) 2 \mathrm{D}$ test. Most $1,25(\mathrm{OH}) 2 \mathrm{D}$ tests $(92 \%)$ were conducted in patients who did not have abnormal PTH or elevated calcium test results.

\section{Prescriptions Subsequent to Nonindicated Vitamin D Testing}

A total of 275 prescriptions for oral vitamin D supplements were provided to 112 (20\%) patients. Nine different vitamin $\mathrm{D}$ prescriptions were provided in a total of 26 different treatment regimens (Table 5). Seventy-three (65\%) prescriptions were for ergocalciferol (vitamin $\mathrm{D}_{2}$ ) and 39 (35\%) were for cholecalciferol (vitamin $\mathrm{D}_{3}$ ). There was no relationship between vitamin $\mathrm{D}$ test result and type or 
Table 3. Demographic and Clinical Characteristics of Patients Who Had Vitamin D Testing in 2015

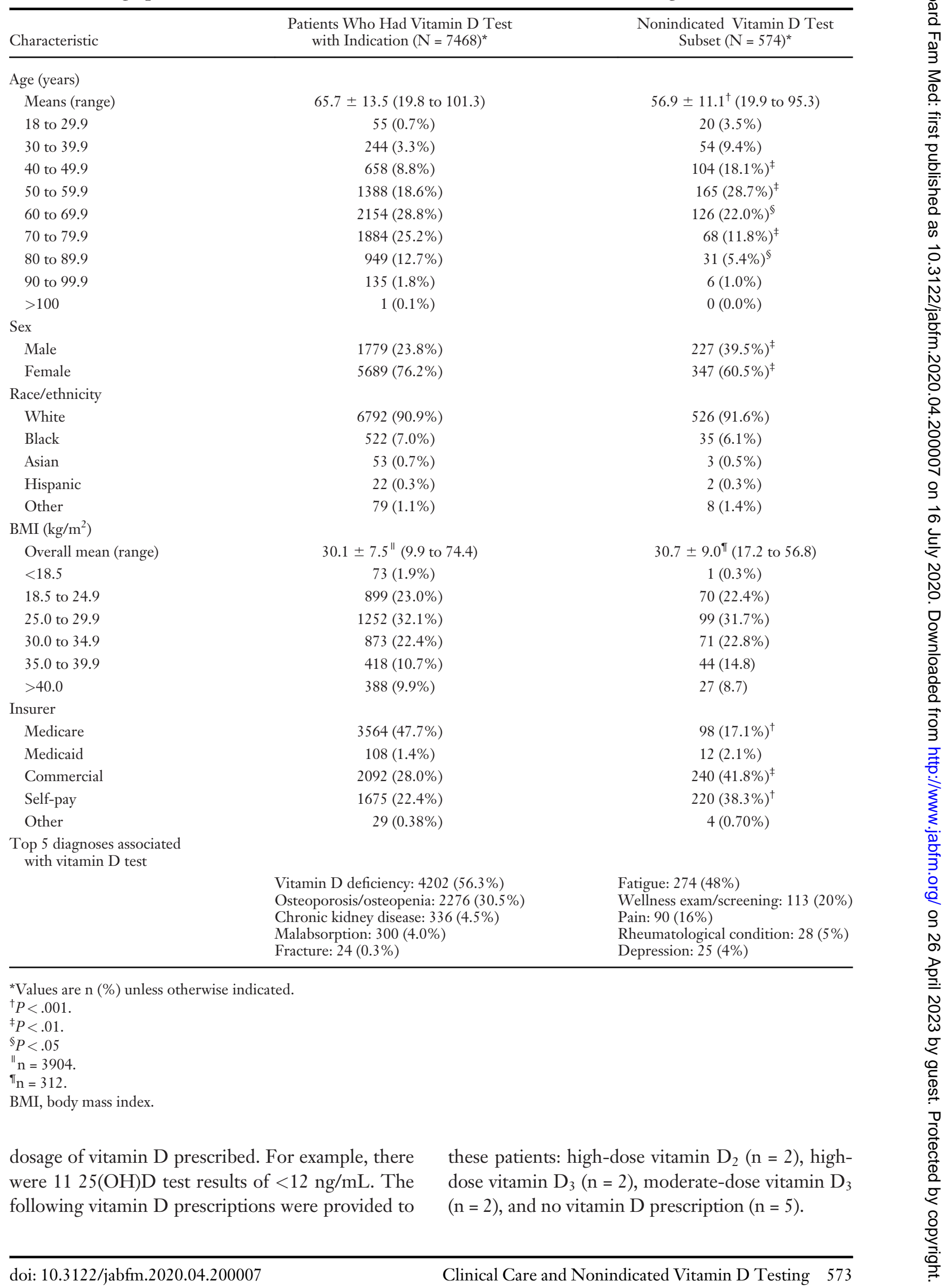


Table 4. Results of Initial Vitamin D Tests in Primary Care Patients in 2015

\begin{tabular}{lcc}
\hline & $\begin{array}{c}\text { Patients Who Had Vitamin D Test with } \\
\text { Indication }(\mathrm{N}=7468), \mathrm{n}(\% \text { of Indicated } \\
\text { Tests) }\end{array}$ & $\begin{array}{c}\text { Nonindicated Vitamin D Test Subset } \\
(\mathrm{N}=574), \mathrm{n}(\% \text { of Nonindicated } \\
\text { Tests) }\end{array}$ \\
\hline Vitamin D deficient $(0$ to $19.9 \mathrm{ng} / \mathrm{mL})$ & $469(6.3 \%)$ & $49(8.6 \%)$ \\
Vitamin D insufficient $(20$ to $29.9 \mathrm{ng} / \mathrm{mL})$ & $1302(17.5 \%)$ & $171(30.0 \%)^{*}$ \\
Normal vitamin D $(30$ to $99.9 \mathrm{ng} / \mathrm{mL})$ & $5658(75.7 \%)$ & $352(61.3 \%)^{*}$ \\
High vitamin D $(>100 \mathrm{ng} / \mathrm{mL})$ & $39(0.5 \%)$ & $2(0.5 \%)$ \\
\hline
\end{tabular}

${ }^{*} P<.01$.

Of the 112 patients who received a vitamin $\mathrm{D}$ prescription, 82 (73\%) had at least 1 follow-up vitamin D test. The type of vitamin D prescription (vitamin $\mathrm{D}_{2}$ or $\mathrm{D}_{3}$ ) was a significant predictor of change in vitamin $\mathrm{D}$ test result $\left(\mathrm{R}^{2}=0.854\right.$, $P<.001$ ) (Figure 2). Patients prescribed vitamin D2 experienced a $68 \%$ decline in vitamin $\mathrm{D}$ test results (range, $-710 \%$ to $48 \%$ change), whereas patients prescribed vitamin D3 experienced a $43 \%$ improvement in vitamin $\mathrm{D}$ test results (range, $-180 \%$ to $430 \%)$. There was no significant interaction between type of prescription and time. Half $(50 \%)$ of patients with low initial vitamin D test results achieved normal test results during the 24- month observation. The likelihood of achieving normal vitamin $\mathrm{D}$ results was significantly higher in patients prescribed moderate-dose (1000 to 2000 $\mathrm{IU} /$ day) or high-dose ( $\geq 2000 \mathrm{IU} /$ day) vitamin $\mathrm{D}_{3}$ than in those prescribed low-dose (400 to 1000 IU/ day) vitamin $\mathrm{D}_{3}(P=.030)$. There were no high $(>100 \mathrm{ng} / \mathrm{mL}$ ) vitamin $\mathrm{D}$ test results following the provision of vitamin $\mathrm{D}$ prescriptions.

Calcium (without vitamin D) was prescribed to 21 patients $(5 \%)$, and bone resorption inhibitors were prescribed to 15 patients (3\%) who had nonindicated vitamin $\mathrm{D}$ tests. Calcimimetic medications (eg, cinacalcet) were not prescribed to any patients in the subset.

Figure 1. Vitamin D-relevant services incurred in the 24 months following a nonindicated vitamin D test. An alluvial diagram showing the flow of vitamin D-relevant service utilization for 2 years following a nonindicated vitamin D test in 2015.

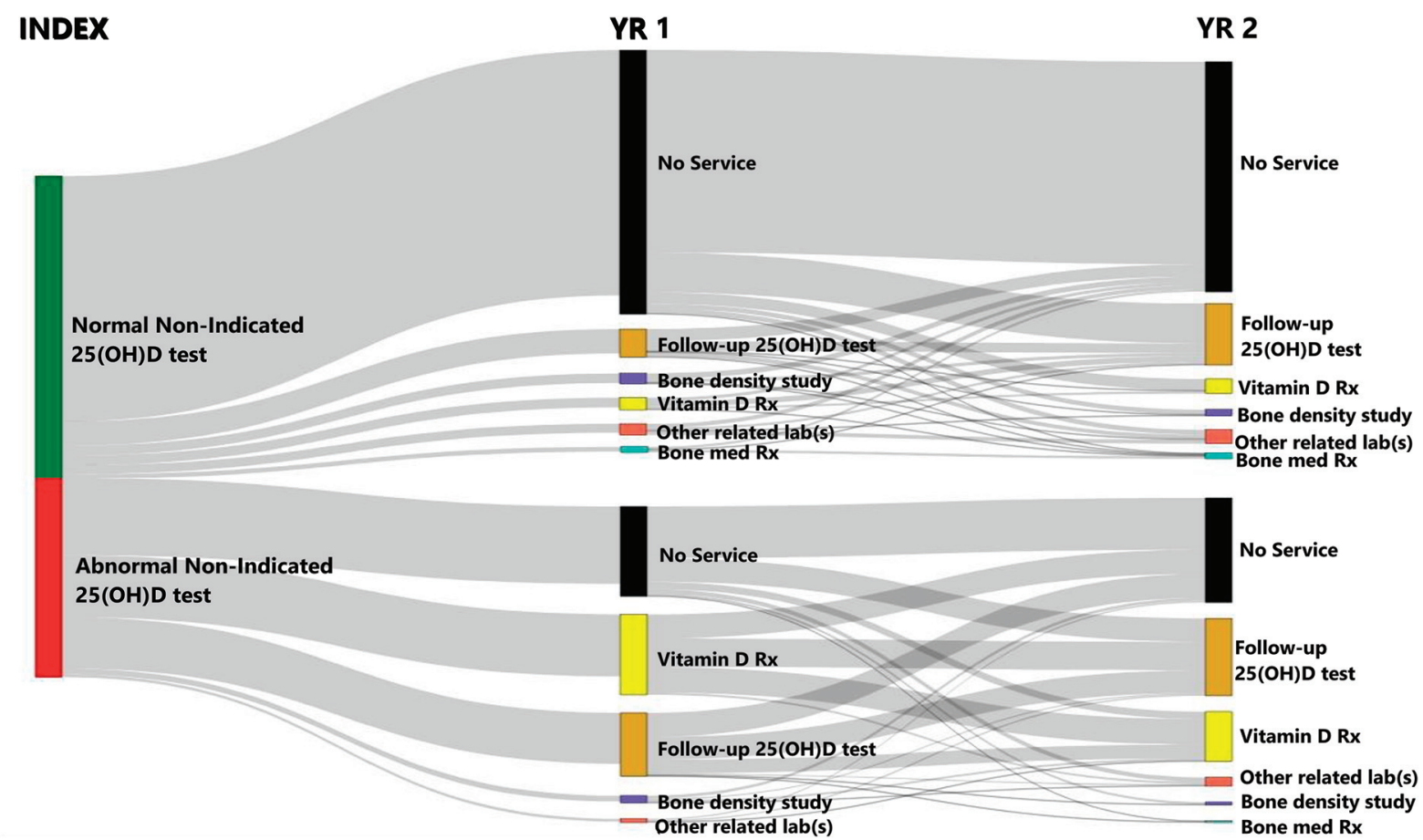


Table 5. Vitamin D Prescriptions Provided to the Subset of Patients Who Had Nonindicated Index Vitamin D Tests in 2015

\begin{tabular}{|c|c|c|c|c|c|}
\hline Form & Dose & Frequency & Duration & $\mathrm{n}$ & Prescription Category \\
\hline \multirow[t]{7}{*}{ Ergocalciferol/vitamin $\mathrm{D}_{2}(\mathrm{n}=73)$} & $50,000 \mathrm{IU}$ & Weekly & 4 weeks & 2 & \multirow[t]{7}{*}{ High-dose vitamin $\mathrm{D}_{2}$} \\
\hline & $50,000 \mathrm{IU}$ & Weekly & 8 weeks & 35 & \\
\hline & $50,000 \mathrm{IU}$ & Weekly & 12 weeks & 20 & \\
\hline & $50,000 \mathrm{IU}$ & Weekly & 16 weeks & 9 & \\
\hline & $50,000 \mathrm{IU}$ & Weekly & 20 weeks & 4 & \\
\hline & $50,000 \mathrm{IU}$ & Weekly & 24 weeks & 2 & \\
\hline & $50,000 \mathrm{IU}$ & Weekly & 48 weeks & 1 & \\
\hline \multirow[t]{20}{*}{ Cholecalciferol/vitamin $\mathrm{D}_{3}(\mathrm{n}=39)$} & $50,000 \mathrm{IU}$ & Daily & 2 months & 1 & \multirow[t]{6}{*}{ High-dose vitamin $\mathrm{D}_{3}$} \\
\hline & $50,000 \mathrm{IU}$ & Weekly & 12 weeks & 1 & \\
\hline & $10,000 \mathrm{IU}$ & Daily & 4 months & 1 & \\
\hline & $5,000 \mathrm{IU}$ & Daily & 3 months & 5 & \\
\hline & $5,000 \mathrm{IU}$ & Daily & 2 months & 1 & \\
\hline & $4,000 \mathrm{IU}$ & Daily & 3 months & 1 & \\
\hline & $2,000 \mathrm{IU}$ & Daily & 10 months & 1 & \multirow[t]{11}{*}{ Moderate-dose vitamin $D_{3}$} \\
\hline & 2,000 IU & Daily & 6 months & 3 & \\
\hline & $2,000 \mathrm{IU}$ & Daily & 4 months & 3 & \\
\hline & $2,000 \mathrm{IU}$ & Daily & 3 months & 4 & \\
\hline & $2,000 \mathrm{IU}$ & Daily & 2 months & 3 & \\
\hline & $2,000 \mathrm{IU}$ & Daily & 1 month & 1 & \\
\hline & $1,000 \mathrm{IU}$ & Daily & 12 months & 1 & \\
\hline & $1,000 \mathrm{IU}$ & Daily & 8 months & 1 & \\
\hline & $1,000 \mathrm{IU}$ & Daily & 6 months & 4 & \\
\hline & $1,000 \mathrm{IU}$ & Daily & 4 months & 2 & \\
\hline & $1,000 \mathrm{IU}$ & Daily & 3 months & 1 & \\
\hline & $400 \mathrm{IU}$ & Daily & 6 months & 1 & \multirow[t]{3}{*}{ Low-dose vitamin $\mathrm{D}_{3}$} \\
\hline & $400 \mathrm{IU}$ & Daily & 3 months & 2 & \\
\hline & $600 \mathrm{mg}$ calcium $+400 \mathrm{IU}$ & Daily & 3 months & 2 & \\
\hline
\end{tabular}

Imaging Subsequent to Nonindicated Vitamin D Testing

Vitamin D-related imaging studies were conducted on 30 patients $(5 \%)$ during the 24 months following nonindicated vitamin $\mathrm{D}$ testing. One patient underwent 2 imaging studies, whereas the remainder had a single imaging study. The majority of imaging studies $(83 \%)$ consisted of multisite dual energy radiograph absorptiometry (DXA), and the remainder consisted of axial-only DXA.

\section{Diagnoses Subsequent to Nonindicated Vitamin D Testing}

During the 24 months following a nonindicated vitamin $\mathrm{D}$ test, a new diagnosis of vitamin $\mathrm{D}$ deficiency or vitamin $\mathrm{D}$ insufficiency was documented for 356 patients (62\%). Of these patients, 107 (21\%) had only normal vitamin D test results during the 24-month observation period. Other vitamin D-related diagnoses documented were osteoporosis (8\%), osteopenia (1\%), osteoporotic fracture $(1 \%)$, pathologic fracture $(0.5 \%)$, stress fracture $(0.5 \%)$, inflammatory bowel disease $(5 \%)$, malabsorption (2\%), and parathyroid/calcium/ phosphate disorder (1\%). There was no difference in the likelihood of receiving these diagnoses based on initial vitamin $\mathrm{D}$ status.

\section{Discussion}

Amid controversy in vitamin $\mathrm{D}$ research and clinical guidelines, vitamin $\mathrm{D}$ testing and prescribing have increased substantially in the past 15 years. ${ }^{10}$ Nonindicated testing has been shown to represent a substantial proportion of this testing and is considered a source of low value health care. ${ }^{6}$ One purpose of this study was to explore downstream consequences of nonindicated vitamin $\mathrm{D}$ testing within primary care of our Southwest Virginia health system. Overall, we observed inconsistency 
Figure 2. Proportion of low and normal vitamin D test results following vitamin D2 and vitamin D3 prescriptions *The highest vitamin $D$ test result attained during the 24 months following a nonindicated index vitamin $D$ test.

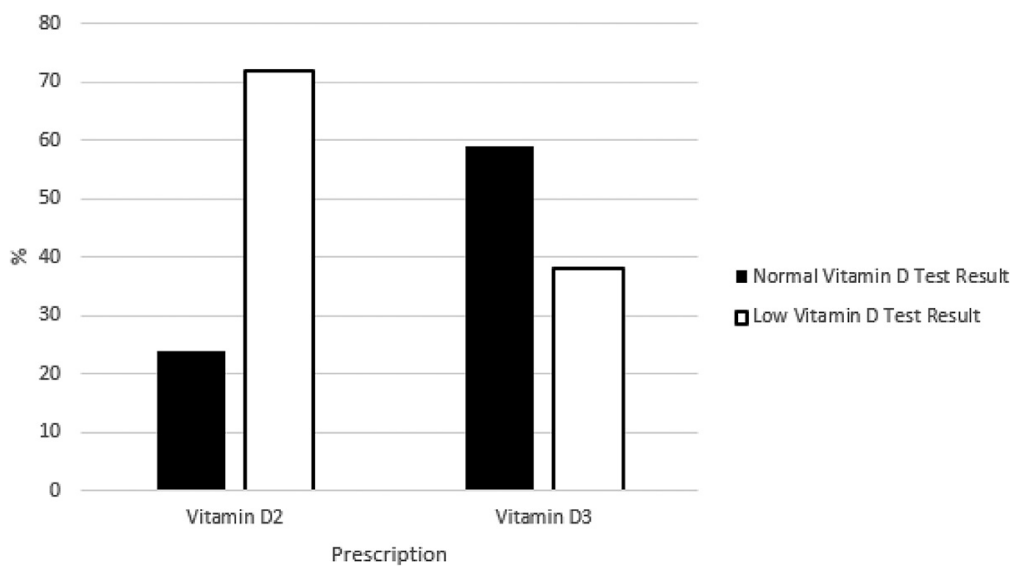

in care, opportunities to improve care, and evidence of a low-value service cascade during the 24 months following a nonindicated vitamin $\mathrm{D}$ test.

\section{Patterns of Care}

Inconsistency in vitamin D-related care has been reported previously ${ }^{30-32}$ and existed in the current study. Numerous care pathways and vitamin D treatment regimens were observed. In addition, the number of follow-up vitamin $\mathrm{D}$ tests, time between vitamin $\mathrm{D}$ tests, and the $25(\mathrm{OH}) \mathrm{D}$ concentration associated with a vitamin $\mathrm{D}$ deficiency diagnosis were highly variable.

We observed the highest inconsistency in care following insufficient vitamin $\mathrm{D}$ test results. Defined as $25(\mathrm{OH}) \mathrm{D}$ of 20 to $29.9 \mathrm{ng} / \mathrm{mL}$ in the present study (Table 2), insufficient test results were associated with the highest rate of follow-up vitamin $\mathrm{D}$ tests (double that of low test results). However, few patients with insufficient test results were given vitamin D prescriptions. It is possible that over-the-counter vitamin D supplements were recommended for patients with insufficient test results, but because only one-third of these patients showed improved vitamin $\mathrm{D}$ test results within the 24-month observation period, issues of documentation, adherence, and effectiveness are all possible. Of note, the definition of vitamin D insufficiency is controversial and not even recognized by all practice guidelines. For instance, the Endocrine Society recognizes $25(\mathrm{OH}) \mathrm{D}$ of 20 to $29.9 \mathrm{ng} / \mathrm{mL}$ as insufficient, ${ }^{8}$ but the National Academy of Medicine does not recognize a vitamin $\mathrm{D}$ insufficient category and states that $25(\mathrm{OH}) \mathrm{D}$ of $20 \mathrm{ng} / \mathrm{mL}$ meets the needs of $97.5 \%$ of the population. ${ }^{9}$ It is also important to consider that many professional organizations have highly variable recommendations related to indicators for vitamin D testing, ${ }^{10}$ which is challenging for clinicians to navigate. ${ }^{3-35} \mathrm{We}$ observed higher average vitamin $\mathrm{D}$ test results $(41.1 \pm 9.3$ $\mathrm{ng} / \mathrm{mL}$ ) and a lower prevalence of severe vitamin $\mathrm{D}$ deficiency $(<1 \%)$ than previous reports. ${ }^{36-38}$ As there are numerous factors that influence vitamin D status, these differences could be based on variability in geography, age, race, adiposity, medication use, socioeconomic status, overall health status, or other factors. For example, our cohort included almost exclusively white patients (who typically have higher vitamin $\mathrm{D}$ than individuals with darker skin pigmentation) and patients with lower $\mathrm{BMI}$ than other cited studies (higher BMI is associated with lower vitamin D). ${ }^{24,25,39,40}$

A few differences in characteristics of patients who had nonindicated initial vitamin D tests compared with those who had indicated vitamin $\mathrm{D}$ tests were identified. The difference in age (nonindicated test patients were younger and less likely to be insured by Medicare) may be due to the exclusion of patients who were recorded as already taking vitamin D supplements. More than 50\% of Americans over 60 years of age have been reported to take vitamin D supplements. ${ }^{41}$ The greater proportion of self-pay and commercially insured patients in the nonindicated test cohort is likely a factor of this younger age-group that is less likely to be insured by Medicare. The higher rate of abnormal vitamin $\mathrm{D}$ test results in the nonindicated test subset may reflect clinicians' clinical instinct related 
to the possibility of low vitamin D. However, it is unclear if identification and treatment of low vitamin $\mathrm{D}$ is clinically valuable in patients without specific indications. ${ }^{7}$

\section{Quality of Care}

We identified some potential opportunities to improve quality of care related to vitamin D. For example, nearly half of low vitamin D test results were not followed up by repeat vitamin $\mathrm{D}$ testing (Figure 1). Monitoring 25(OH)D following low test results and at least 12 weeks of treatment is a common practice recommendation. ${ }^{8,42,43}$ In addition, two-thirds of vitamin $\mathrm{D}$ prescriptions were for vitamin $\mathrm{D}_{2}$ rather than vitamin $\mathrm{D}_{3}$, which has greater bioavailability than vitamin $\mathrm{D}_{2}$ and is more effective in raising $25(\mathrm{OH}) \mathrm{D} .{ }^{44,45}$ As this finding is somewhat recent, it is not reflected in major vitamin $\mathrm{D}$ guidelines, which describe both forms as suitable treatment options. ${ }^{8,9}$

One-fifth of patients given a new diagnosis of vitamin $\mathrm{D}$ deficiency or insufficiency did not have low vitamin $\mathrm{D}$ test results. This may reflect the existing controversy around $25(\mathrm{OH}) \mathrm{D}$ values. ${ }^{33}$ Clinicians may have also assigned such a diagnosis to obtain insurance reimbursement for tests, which has been reported previously. ${ }^{34}$

\section{Health Services Cascade}

Abnormal test results have been described as triggering a cascade process by which a number of referrals and additional investigations arise. ${ }^{46}$ The volume of vitamin D-relevant services (an average of 1.6 services per patient) that followed a nonindicated vitamin D test suggests that a similar cascade occurs within our health system. Another consideration is that, during 2015, our health system had a limited endocrinology service and did not have a nephrology service, so referrals for these services were made outside of our health system. Thus, we are likely missing vitamin D-relevant health services that were not documented in our EHR.

Some of the services provided subsequent to a nonindicated vitamin $\mathrm{D}$ test can themselves be described as low value. For example, more than half of the 320 follow-up tests ordered (up to 7 followup tests in 24 months) did not meet our criteria (based on Choosing Wisely) for an indicated vitamin $\mathrm{D}$ test. In addition, the majority of $1,25(\mathrm{OH}) 2 \mathrm{D}$ tests were conducted in patients who did not fulfill the Choosing Wisely indications for this test (hypercalcemia and/or abnormal PTH). ${ }^{4}$

The financial impact of nonindicated vitamin D testing can be significant. Based on the charge for an outpatient vitamin D test at Carilion Clinic $(\sim 278$ in 2015$)$, the sum of all vitamin $D$ charges for tests ordered by primary care clinicians in this health system in 2015 is estimated at $\$ 2,946,800$. Over \$240,000 was charged for vitamin D testing within the nonindicated test subset. Downstream health services and associated resources for these nonindicated tests may result in additional financial burden. In addition, the overall culture of low-value care is in itself considered harmful. Consequences such as increased false-positive test results, enhanced health risk related to follow-up services, emotional impact to patients, increased resources required to administer services, and decreased opportunity for higher value care have been observed following low-value health services. ${ }^{26,29}$

A strength of this study is the use of EHR data to explore downstream impacts of a common nonindicated laboratory test within a large health system, similar to that which has been performed with other lowvalue care services. ${ }^{47,48} \mathrm{We}$ are not aware of other published studies that have examined downstream consequences of low-value vitamin D tests. Although individual chart review was not performed in this study, Isaac et al. ${ }^{40}$ recently observed only minor differences in low-value care services identified via automated EHR search and individual chart review.

We acknowledge some limitations in the current study. By nature, EHR research makes assumptions about clinician behavior without necessarily knowing intent. To that end, our results provide a broad description of health service patterns without consideration of details that may have factored into clinician decisions and behaviors. Some tests that we classified as nonindicated may actually have been indicated, and vice versa. We were also unable to account for over-the-counter vitamin D supplements (unless reported in patients' medication list), diet, and sun exposure. Finally, we acknowledge that service chronology does not necessarily reflect downstream effects but instead interprets the high volume of vitamin D-relevant services as suggestive of a causal association. Overall, our results provide one of the first attempts to capture downstream health service use following nonindicated vitamin $\mathrm{D}$ testing. The broad patterns we observed generate hypotheses for future investigations. 


\section{Conclusions}

In 2015, vitamin D tests were ordered for $10 \%$ of adult primary care patients within our Southwest Virginia health system, with approximately onequarter yielding abnormal results. In a subset of these patients who had nonindicated vitamin D tests, there seems to be high variability in care pathways and some opportunities to improve care quality. We also observed evidence of a low-value service cascade during the 24 months following a nonindicated vitamin $\mathrm{D}$ test. Taken together, these results provide insight into primary care clinicians' practice patterns in light of evolving research and conflicting guidelines related to the clinical management of vitamin D status. Possible interventions to improve care and reduce inconsistency related to vitamin $\mathrm{D}$ services could include clinician education and feedback, development of clinical pathways related to the identification and treatment of vitamin D-related abnormalities, modifications to EHR default settings and prompts, and patient education. Further research on the downstream impacts of nonindicated vitamin D testing is needed.

To see this article online, please go to: bttp://jabfm.org/content/ 33/4/569.full.

\section{References}

1. Shrank WH, Rogstad TL, Parekh N. Waste in the US health care system: estimated costs and potential for savings. JAMA 2019;322:1501-9.

2. Colla CH, Mainor AJ, Hargreaves C, Sequist T, Morden N. Interventions aimed at reducing use of low-value health services: a systematic review. Med Care Res Rev 2017;74:507-50.

3. Miller G, Rhyan C, Beaudin-Seiler B, HughesCromwick P. A framework for measuring low-value care. Value Health 2018;21:375-9.

4. Choosing Wisely. Available from: http://www. choosingwisely.org/. Accessed November 2019.

5. Reschovsky JD, Rich EC, Lake TK. Factors contributing to variations in physicians' use of evidence at the point of care: a conceptual model. J Gen Intern Med 2015;30:555-61.

6. American Society for Clinical Pathology Choosing Wisely recommendations. Available from: http:// www.choosingwisely.org/clinician-lists/americansociety-Clinical-Pathology-population-basedscreening-for-vitamin-d-deficiency/. Published February 21, 2013. Accessed October 2019.

7. LeFevre ML. Screening for vitamin D deficiency in adults: U.S. Preventive Services Task Force recommendation statement. Ann Intern Med 2015;162:133-40.

8. Holick MF, Binkley NC, Bischoff-Ferrari HA, et al. Evaluation, treatment, and prevention of vitamin D deficiency: an Endocrine Society Clinical practice guideline. J Clin Endocrinol Metab 2011;96:1911-30.

9. Ross AC, Manson JE, Abrams SA, et al. The 2011 report on dietary reference intakes for calcium and vitamin D from the Institute of Medicine: what clinicians need to know. J Clin Endocrinol Metab 2011;96:53-8.

10. Rockwell M, Kraak V, Hulver M, Epling J. Clinical management of low vitamin D: a scoping review of physicians' practices. Nutrients 2018;10:493.

11. Virginia low value services report (2016). Available from: https://www.vhi.org/apcd/Virginia\%20Low \%20Value\%20Services\%20Report.pdf.

12. Bilinski KL, Boyages SC. The rising cost of vitamin $\mathrm{D}$ testing in Australia: time to establish guidelines for testing. Med J Aust 2012;197:90.

13. Colla CH, Morden NE, Sequist TD, Mainor AJ, Li $\mathrm{Z}$, Rosenthal MB. Payer type and low-value care: comparing Choosing Wisely services across commercial and Medicare populations. Health Serv Res 2018;53:730-746.

14. Bilinski K, Boyages S. Evidence of overtesting for vitamin $\mathrm{D}$ in Australia: an analysis of 4.5 years of Medicare Benefits Schedule (MBS) data. BMJ Open 2013;3:e002955.

15. Bilinski K, Boyages $\mathrm{S}$. The rise and rise of vitamin D testing. BMJ 2012;345:e4743.

16. Caillet P, Goyer-Joos A, Viprey M, et al. Increase of vitamin D assays prescriptions and associated factors: a population-based cohort study. Sci Rep 2017;7:10361.

17. Shahangian S, Alspach TD, Astles JR, Yesupriya A, Dettwyler WK. Trends in laboratory test volumes for Medicare Part B reimbursements, 2000-2010. Arch Pathol Lab Med 2014;138:189-203.

18. Khalifa M, Zabani I, Khalid P. Exploring lab tests over utilization patterns using health analytics methods. Stud Health Technol Inform 2016;226: 190-193.

19. Colla CH, Morden NE, Sequist TD, Schpero WL, Rosenthal MB. Choosing Wisely: prevalence and correlates of low-value health care services in the United States. J Gen Intern Med 2015;30:221-228.

20. Excellus: low value vitamin $D$ testing in upstate NY. Available from: https://www.bcbs.com/news/ press-releases/most-people-dont-need-vitamin-dtesting. Accessed November 2019.

21. Rodd C, Sokoro A, Lix LM, et al. Increased rates of 25-hydroxy vitamin D testing: dissecting a modern epidemic. Clin Biochem 2018;59:56-61.

22. Woodford HJ, Barrett S, Pattman S. Vitamin D: too much testing and treating?. Clin Med 2018;18:196-200.

23. Mafi JN, Russell K, Bortz BA, Dachary M, Hazel WA, Jr., Fendrick AM. Low-cost, high-volume health services contribute the most to unnecessary health spending. Health Aff (Millwood)2017;36:1701-1704. 
24. Rozario NL, Sparling A, Burns R, et al. Modifying provider vitamin $\mathrm{D}$ screening behavior in primary care. J Am Board Fam Med 2020;33:252-261.

25. Carter EA, Morin PE, Lind KD. Costs and trends in utilization of low-value services among older adults with commercial insurance or Medicare advantage. Med Care 2017;55:931-939.

26. Krasowski MD, Chudzik D, Dolezal A, et al. Promoting improved utilization of laboratory testing through changes in an electronic medical record: experience at an academic medical center. BMC Med Inform Decis Mak 2015;15:11.

27. Naugler C, Ma I. More than half of abnormal results from laboratory tests ordered by family physicians could be false-positive. Can Fam Physician 2018;64:202-203.

28. Webster BS, Choi Y, Bauer AZ, Cifuentes M, Pransky G. The cascade of medical services and associated longitudinal costs due to nonadherent magnetic resonance imaging for low back pain. Spine 2014;39:1433-1440.

29. von Elm E, Altman DG, Egger M, Pocock SJ, Gøtzsche PC, Vandenbroucke JP; for the STROBE Initiative. The Strengthening the Reporting of Observational Studies in Epidemiology (STROBE) statement: guidelines for reporting observational studies. Ann Intern Med 2007;147:573-577.

30. Morgen EK, Naugler C. Inappropriate repeats of six common tests in a canadian city: a population cohort study within a laboratory informatics framework. Am J Clin Pathol 2015;144:704-712.

31. Pepper KJ, Judd SE, Nanes MS, Tangpricha V. Evaluation of vitamin D repletion regimens to correct vitamin D status in adults. Endocr Pract 2009;15:95-103.

32. Caillet P, Souberbielle JC, Jaglal SB, et al. Vitamin $\mathrm{D}$ supplementation in a healthy, middle-aged population: actual practices based on data from a French comprehensive regional health-care database. Eur J Clin Nutr 2013;67:1133-1137.

33. Tarn DM, Paterniti DA, Wenger NS. Clinician recommendations in the face of scientific uncertainty: an analysis of audio-recorded discussions about vitamin D. J Gen Intern Med 2016;31:909-917.

34. Epling JW, Mader EM, Roseamelia CA, Morley CP. Emerging practice concerning vitamin D in primary care. Qual Health Res 2015;25:1005-1012.

35. Hofstede H, van der Burg HAM, Mulder BC, et al. Reducing unnecessary vitamin testing in general practice: barriers and facilitators according to general practitioners and patients. BMJ Open 2019;9:e29760.

36. Genzen JR, Gosselin JT, Wilson TC, Racila E, Krasowski MD. Analysis of vitamin D status at two academic medical centers and a national reference laboratory: result patterns vary by age, gender, season, and patient location. BMC Endocr Disord 2013;13:52-52.
37. Bailey BA, Manning T, Peiris AN. Vitamin D testing patterns among six Veterans Medical Centers in the Southeastern United States: links with medical costs. Mil Med 2012;177:70-76.

38. Stratton-Loeffler MJ, Lo JC, Hui RL, Coates A, Minkoff JR, Budayr A. Treatment of vitamin D deficiency within a large integrated health care delivery system. J Manag Care Pharm 2012;18:497-505. Available from: https://pubmed.ncbi.nlm.nih.gov/ 22971203/.

39. Petrilli CM, Henderson J, Keedy JM, et al. Reducing unnecessary vitamin D screening in an academic health system: what works and when. Am J Med 2018;131:1444-1448.

40. Isaac T, Rosenthal MB, Colla CH, et al. Measuring overuse with electronic health records data. Am J Manag Care 2018;24:19-25. Available from: https://pubmed.ncbi.nlm.nih.gov/29350509/.

41. CDC. Dietary supplement usage among U.S. adults. Available from: https://www.cdc.gov/nchs/ data/databriefs/db61.htm. Accessed November 2019.

42. Płudowski P, Karczmarewicz E, Bayer M, et al. Practical guidelines for the supplementation of vitamin D and the treatment of deficits in Central Europe-recommended vitamin D intakes in the general population and groups at risk of vitamin D deficiency. Endokrynol Pol 2013;64:319-327.

43. American Academy of Family Physicians. Clinical preventive service recommendation-vitamin D deficiency. Available from: https://wwwaafporg/ patient-care/Clinical-recommendations/all/vitaminD-deficiencyhtml. Accessed January 2020.

44. Shieh A, Chun RF, Ma C, et al. Effects of high-dose vitamin D2 versus D3 on total and free 25-hydroxyvitamin D and markers of calcium balance. J Clin Endocrinol Metab 2016;101:3070-3078.

45. Tripkovic L, Lambert H, Hart K, et al. Comparison of vitamin D2 and vitamin D3 supplementation in raising serum 25-hydroxyvitamin D status: a systematic review and meta-analysis. Am J Clin Nutr 2012;95:1357-1364.

46. Houben PH, van der Weijden T, Winkens B, Winkens RA, Grol RP. Pretest expectations strongly influence interpretation of abnormal laboratory results and further management. BMC Fam Pract 2010;11:13.

47. Ganguli I, Lupo C, Mainor AJ, et al. Prevalence and cost of care cascades after low-value preoperative electrocardiogram for cataract surgery in feefor-service Medicare beneficiaries. JAMA Intern Med 2019;179:1211-1219.

48. Bhatia RS, Bouck Z, Iyers NM, et al. Electrocardiograms in low-risk patients undergoing an annual health examination. JAMA Intern Med 2017;177:1326-1335. 